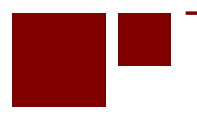

C E N T E R for RETIREMENT RES E A R C H at BOSTON COLLEGE

\title{
OVERCOMING BARRIERS TO LIFE INSURANCE COVERAGE: A BEHAVIORAL APPROACH
}

\author{
Anek Belbase, Norma B. Coe, and April Yanyuan Wu \\ CRR WP 2015-5 \\ Released: June 2015 \\ Center for Retirement Research at Boston College \\ Hovey House \\ 140 Commonwealth Avenue \\ Chestnut Hill, MA 02467 \\ Tel: 617-552-1762 Fax: 617-552-0191 \\ http://crr.bc.edu
}

Anek Belbase is a research project manager at the Center for Retirement Research at Boston College. Norma B. Coe is an assistant professor of health services at the University of Washington. April Yanyuan Wu is a researcher at Mathematica Policy Research. The research reported herein was pursuant to a grant from Prudential Financial. The findings and conclusions expressed are solely those of the authors and do not represent the views of Prudential Financial, the University of Washington, Mathematica Policy Research, or Boston College.

(C) 2015, Anek Belbase, Norma B. Coe, and April Yanyuan Wu. All rights reserved. Short sections of text, not to exceed two paragraphs, may be quoted without explicit permission provided that full credit, including $(\subset$ notice, is given to the source. 


\begin{abstract}
About the Center for Retirement Research
The Center for Retirement Research at Boston College, part of a consortium that includes parallel centers at the University of Michigan and the National Bureau of Economic Research, was established in 1998 through a grant from the Social Security Administration. The Center's mission is to produce first-class research and forge a strong link between the academic community and decision-makers in the public and private sectors around an issue of critical importance to the nation's future. To achieve this mission, the Center sponsors a wide variety of research projects, transmits new findings to a broad audience, trains new scholars, and broadens access to valuable data sources.
\end{abstract}

Center for Retirement Research at Boston College

Hovey House

140 Commonwealth Ave

Chestnut Hill, MA 02467

Tel: 617-552-1762 Fax: 617-552-0191

http://crr.bc.edu

Affiliated Institutions:

The Brookings Institution

Massachusetts Institute of Technology

Syracuse University

Urban Institute 


\begin{abstract}
While life insurance purchase decisions have long been studied, we still do not know how people decide if they need insurance or how much they need. Using in-depth interviews, we peer into the black box of employee decision-making to learn what people know about this employeebenefit, and how they decide if it is of value to them. We find that individuals understand the need for life insurance but find many behavioral economic barriers to getting adequate coverage, including mental accounting, money illusion, and the strong role of defaults. We then conduct an online experiment of the hypothetical employee-benefit purchase scenario and find a few, simple interventions could help individuals better decide their life insurance needs.
\end{abstract}




\section{Introduction}

Researchers have been examining the life insurance decision for almost 50 years, culminating in a long, but not yet unified, literature aimed at explaining life insurance demand (see Zietz 2003 for a review). Most of this work has focused on traditional economic factors for the demand for life insurance, such as age, education, children, net worth, Social Security, stock returns, and price of the insurance product. While most of these factors have been found to have a significant correlation with life insurance purchase or amount, most of them have also been found to have both a negative and a positive relationship, depending on the study in question.

The nature of life insurance and the risk it insures make the coverage decision very susceptible to decision limitations posited by behavioral finance, yet these explanations for the low coverage remain largely unexplored. ${ }^{1}$ For example, early death is not pleasant to think about, making the coverage decision prone to procrastination or other avoidance strategies. It is also a relatively low-probability event, which decision-makers are prone to over-discount. Benefits are often framed in terms of a large lump-sum, which could suffer from money illusion problems. While the group life insurance market comprises around 40 percent of the overall life insurance market, very little is known about how individuals decide their life insurance needs and select their benefits packages, or if their selections are optimal for their situation.

This study is two-fold. First, we conduct in-depth interviews to shed light into the prevalence of behavioral finance concepts at play when employees make decisions regarding their life insurance benefits. This allows us to identify behavioral barriers to getting appropriate coverage levels. We explore the prevalence of mental short-cuts, rules of thumb, risk misperception, as well as assess the potential influence of anchoring, framing, and signaling in the take-up and coverage decisions.

Second, we conduct a hypothetical on-line experiment to test whether behavioral finance tools could impact decision-making when selecting life insurance coverage as part of an employee-benefits package. We develop several "treatment” enrollment scenarios based on the barriers identified in the interviews and grounded in well-established behavioral finance concepts (Kahneman and Tversky 1979, 1986; Kahneman et al. 1982; Mussweiler et al. 2004; Wilson et al. 1996; Mullainathan and Thaler 2000). We estimate the effect of each treatment on both the

\footnotetext{
${ }^{1}$ Burnett and Palmer (1984) examined non-traditional explanations for the demand for life insurance, including lifestyle, fatalism, religious salience, and socialization preferences, but not all of these concepts do not easily align with behavioral finance theories.
} 
intensive margin (insurance take-up) and the extensive margin (the amount of insurance

selected), compared to a baseline enrollment scenario based on the existing communication practices of a major insurance provider.

This study is an important first-step in not only understanding how individuals decide on their life insurance coverage, but also identifying potential interventions that could help counter the behavioral barriers that are leaving employees increasingly financially vulnerable. The benefit landscape will continue changing due in part to the Affordable Care Act (ACA). The recent emphasis on health insurance may mean that other important insurance benefits increasingly get short-changed in the future. Identifying and implementing appropriate interventions now could help to increase the financial stability of households.

This paper continues as follows. Section 2 discusses the life insurance market and some recent trends within the employer-sponsored group benefits landscape. Section 3 discusses how individuals decide on life insurance coverage, as illuminated by 24 in-depth interviews. Section 4 discusses a hypothetical on-line intervention to test the ability to overcome the behavioral barriers to optimal decision making identified in section 3. Section 5 concludes that there are a lot of behavioral barriers to determining adequate life insurance coverage, and we have identified several promising and easy interventions that can assist individuals make appropriate choices.

\section{The Life Insurance Market}

There are three primary places individuals buy life insurance. The individual market for life insurance accounts for 57 percent of all life insurance dollars in force at the end of 2011. Group life insurance, typically offered through an employer, accounts for 42 percent of the dollars and almost 40 percent of the policies in-force in 2011. Finally, credit life insurance, which pays the balance on long-term loans (such as mortgages) in the case of death, rounds out the market, but accounts for only 8 percent of the policies, and less than 1 percent of the dollars (ACLI 2013). One-in-four families in the U.S. rely on employer-sponsored group plans (LIMRA 2010).

Group life insurance premiums may be lower due to risk pooling or through employercontributions to the premium. Many employers offer a base level of life insurance, whose premiums are covered by the employer, called company-sponsored insurance. In part due to the company-sponsored products, it appears that the group life insurance market is thriving. 
According to the National Compensation Survey (BLS 2013), 72 percent of full-time workers in private industry have access to life insurance benefits, rising to 90 percent of state and local government workers. ${ }^{2}$ Take up rates among employees are almost universal, generally in the high-90 percent range, across industry, worker characteristics, wages, and union status (BLS 2013, Table 5). However, this says nothing about the adequacy of the coverage. Companysponsored insurance levels are typically 1-2 times employee salary, when most needs estimators calculate that 5-8 times salary as adequate coverage (Couch 2011).

Employers may also offer supplemental life insurance policies, where employees can buy additional life insurance. The premiums may or may not be lower than those in the individual market, but they may have higher benefit levels without requiring a medical exam (medical underwriting) than the individual market. Individuals may also like paying premiums directly through their paycheck, or the ease of finding the company and the pricing information, since 80 percent of households do not have an insurance agent or broker to turn to for individual purchase (LIMRA 2010).

However, the group benefits landscape is changing dramatically. The menu of available options has grown; employers are paying for fewer benefits; and the responsibility for selecting the benefit package has been increasingly left to the employee. While the take-up of group life insurance remains high, we have seen a considerable drop in the number of new group policies purchased over the past decade. Between 2001 and 2011, the number of all life insurance policies purchased dropped by almost 20 million, half of that drop was from the group market. There has been an overall drop in life insurance coverage as well. According to LIMRA (2010), 30 percent of households have no life insurance coverage, up by 8 percentage points in just 6 years, and half of households feel they need more life insurance.

\section{How Workers Decide on Their Life Insurance Coverage}

While traditional economic demand factors have been well-researched, the nature of life insurance and the risk it insures make the coverage decision very susceptible to decision limitations posed by behavioral finance. This first analysis allows us to peer into the black-box

\footnotetext{
${ }^{2}$ Access for part-time employees is quite limited, however, with 14 percent of part-time private industry and 23 percent of part-time state and local government employees having access to employer-sponsored life insurance.
} 
of employee decision-making and identify what, if any, behavioral finance concepts are at play in the group benefits arena.

\subsection{Methodology and Data}

We conducted a series of 24 in-depth telephone interviews with consumers regarding their choices of whether to purchase voluntary supplemental life insurance benefits available to them through their workplace. The interviews explored how these benefits are presented to employees, what features attract buyers, and what barriers exist for those who elected not to purchase the insurance coverage. Consumers were also asked about their perceptions of the adequacy of their life insurance and disability insurance coverage and how this compares to assessments of their health, auto, or homeowners insurances. In order to explore decisionmaking in the context of behavioral economics, the questioning attempts to uncover: 1) How consumers perceive the threat of death: the likelihood of experiencing this event and the financial consequences; 2) The perceived adequacy of insurance in mitigating the financial consequences of death; 3) Mental accounting and other shortcuts consumers use to value insurance coverage.

Professional interviewers at Greenwald \& Associates conducted the telephone interviews between December 2011 and March 2012. Nearly all of the interviews took place in the evening and lasted approximately 45 minutes. The interview script can be found in Appendix A. In order to get a sample of individuals who are most like employees making the life insurance coverage decision, we required them to be 21 and over, employed full-time, have household income between $\$ 10,000$ and $\$ 250,000$ annually, and state that they are at least somewhat involved in making household financial decisions. In addition, we asked whether their current employer offered voluntary life insurance coverage, regardless of whether or not it was purchased by the respondent.

Table 1 outlines the descriptive statistics of the sample, as well as the sub-sample of parents. ${ }^{3}$ Nearly all of the respondents are married and most had children. The largest share of respondents has household incomes between \$50,000 and \$150,000 and household assets between $\$ 50,000$ and $\$ 200,000$. The parents in our sample have slightly lower net worth than the overall sample and as such, report being more likely to live paycheck-to-paycheck, as opposed to having a rainy day fund or saving on a regular basis. At the same time, the parents in

\footnotetext{
${ }^{3}$ Additional comparisons were made by sex, but overall men and women responded very similarly.
} 
our sample exhibit signs of being more risk averse, as shown by their lower reported probability of taking high deductible auto and health insurance plans.

All respondents had supplemental life insurance offered through their employers. 77 percent of the sample had life insurance; almost half of the sample purchase additional coverage through work and just over half of the sample purchase it via an alternative source, such as a previous employer, individual market, or union.

\subsection{Life Insurance: The Purchase Decision}

\subsubsection{Whether to Buy}

The first step is to examine how employees decide whether they would purchase life insurance. Our data suggest that individuals do not spend much time on the decision; over 40 percent of the sample spends less than 30 minutes thinking about their life insurance purchases. Further, individuals do not often revisit their life insurance decision. Most state that they do not think about it often, although about one-quarter of the sample indicates that they think about it during annual benefit renewal. Individuals also think about life insurance when one would expect them to: when they start a job, when the employer policy changes, and with good news in their life (marriage, children).

However, there seems to be little need to convince people that they need life insurance. As one respondent put it, life insurance is "almost required or at least highly recommended" and something "most people have."

\subsubsection{How Much to Purchase}

While the need for life insurance seems widely understood, how to determine an adequate level of benefits remains more of a mystery to potential purchasers. Very few discuss this matter with family (about one-quarter) or co-workers, or seek professional advice. Over half of the sample says expert advice would be of interest, yet many do not use advice made available to them during the employee-benefit roll-out period.

Our data suggests that many people are engaged in well-defined mental accounting. Almost 45 percent of the sample indicate that in their budgetary framework, they first decide on

how much they need to spend on other necessities - including health and auto insurance - before determining how much they have left to buy life insurance, as illustrated in Figure 1. Individuals 
in this category are also more likely to report that they are not adequately insured or are less likely to have supplemental life insurance. The same percent of respondents indicate that they decide how much life insurance they need and then buy the right coverage. Finally, only 11 percent indicate that they decided how much to purchase based on what "feels right."

Since life insurance is framed as a lump-sum payout (or future asset), most interviewees indicate that, in determining how much coverage they wanted, they think about big-ticket items (future liabilities) they would want their family to be able to pay off upon their death. Within this framework, easily recallable items like the monthly mortgage are more likely to be considered than less obvious expenses like retirement savings. Figure 2 illustrates the majority chose paying off the mortgage, while almost half want to insure their children's college tuition. Virtually no one states that maintaining the families' lifestyle or continuing retirement saving for the surviving spouse are part of their determination process.

\subsubsection{Potential Variations in the Life Insurance Product}

The interviews offered hypothetical variations on the current life insurance policy, such as including reward points, changing the payout stream, or pairing life insurance with other insurance policies. Overall, respondents show little interest in changing the current policy format, perhaps since individuals seem to understand what they are purchasing. One potential change that was of interest to almost half of the individuals interviewed is receiving the payout in an annuity stream instead of a lump sum. The preference seems to be tied to what they want their survivors to do with the money. A lump sum is preferred only if they want their survivors to exclusively pay off debt and meet significant financial goals; the annuity is of interest if they want to help their survivors with living expenses.

\section{Does Behavioral Economics Tell Us How to Help People Figure Out How Much Life Insurance to Buy?}

These interviews find that individuals generally know what life-insurance is for, and accept the need for life-insurance, but find it hard to figure out an adequate coverage level. We identified numerous potential barriers to optimal decision making through these interviews. The question then becomes to identify tools that can assist individuals to overcome these barriers and decide on appropriate coverage levels. 
Inertia: When faced with the difficult calculation of how much life insurance is needed, individuals may just follow the status quo from a previous decision or avoid making a decision altogether. For example, one respondent said he picked his insurance amount 20 years ago in his first job, and has not revisited the decision since. In order to help individuals overcome inertia, we propose testing defaults.

Mental Accounting: Individuals use mental shortcuts in order to help them determine how much life insurance they need quickly. The most common method reported was to rely on the rule of thumb of paying off their mortgage upon their death. To help individuals counter the inadequate coverage level dictated by these shortcuts, we propose testing treatments following two approaches: 1) attempting to break existing mental accounts by re-framing life insurance as a

product to replace income 2) improving existing shortcuts by presenting checklists which include less salient debt.

Money Illusion: Because the benefits of life insurance are presented as a lump-sum amount, individuals could under estimate how much is needed due to the difference between what they are insuring (the future stream of earnings) and how their insurance benefit is paid. To help individuals counter this problem, we propose testing providing annuity information.

Anchoring: Respondents report picking their coverage based on the per-paycheck price ("less than a trip to Starbucks”), we propose testing the role of personalized coverage estimates, a link to an on-line insurance estimator, and checklists listing average debt amounts.

Signaling: Respondents report picking their level based on assumptions about the adequacy of the company-provided insurance, we propose testing the role of defaults and higher employer-provided options.

\subsection{The Experiment Methodology}

\subsubsection{The Treatments}

To test whether ideas from behavioral finance might improve life insurance decision, we develop 8 benefit enrollment scenarios: one baseline scenario, and 7 "treatment” scenarios. Each scenario mimics a real-world benefit enrollment experience, and starts with the following text: "Imagine you are enrolling in benefits for a new employer. You're offered the chance to buy life and disability insurance as part of your benefit package. Please read through each option and select the one you'd be most likely to pick." 
The baseline scenario goes on to introduce life insurance benefits using the language used by a major life insurance provider in the group-benefits setting:

"You've worked hard to build a good life. There's a lot to protect. Now is the perfect time to evaluate your life insurance needs so your loved ones can live forward with their hopes and dreams.”

Participants are then asked to pick life insurance coverage from no coverage to coverage worth 12 times their annual pay. Each coverage option is presented with the multiple of pay covered, the lump-sum equivalent amount, and the cost of the coverage in dollars per paycheck, using actual prices as provided by the major provider.

Treatment scenarios can differ from the baseline scenario in three ways: 1) by providing additional information in the introductory section; 2) by presenting a different set of coverage options; or 3) by defaulting people into a particular option. The treatments themselves are based on well-established behavioral-finance concepts that are expected to overcome behavioral hurdles to effective decision-making (Kahneman and Tversky, 1979, 1986; Kahneman, Slovic, Tversky, 1982, Strack and Mussweiler, 2004; Mullainathan and Thaler, 2000). Table 2 lists each of the scenarios used in this study.

\subsubsection{The Experiment}

The experiment is conducted by administering on online survey to members of the Knowledge Networks internet panel. All panelists are asked to answer several questions related to their income, spouse's income, family structure, and paycheck frequency. To participate in this study, panelists needed to be employed at the time of the survey and earn at least $\$ 25,000$ annually. 8,466 such panelists were sent out the survey, and 4,581 members (54 percent), responded to the survey, which yielded an average of 416 responses per life insurance scenario. ${ }^{4}$ Table 3 compares demographic information between respondents and non-respondents, as well as the population between the ages of 18 and 75, earning more than $\$ 25,000$ a year, from the Current Population Survey (2011). People who responded to the survey were more likely to be male, married, older, more educated, and had a higher income compared to non-respondents. The respondent sample is skewed towards older respondents compared to the overall population - who earn more, are more likely to be married.

\footnotetext{
${ }^{4}$ This study focuses on benefits provided at the workplace, so responses from people over 75 years of age (about 10) are excluded from the analysis.
} 
Participants are then randomly assigned to one of the 8 benefit enrollment scenarios. To account for the concern that some participants might simply pick the first or last available option, the order of the coverage options is also randomized to either be ascending (no coverage first) or descending (highest coverage option first). We also ask an open ended question to solicit reasons for the participants' coverage elections. The complete survey is presented in Appendix B. The survey was fielded for two weeks in December 2012.

Since panelists were randomly assigned to a scenario, the number of responses varied between the groups, from a high of 448 responses to a low of 382 responses. Data quality tests suggest the data are near complete and the randomization successful: less than 1 percent of respondents skipped or refused to answer one or more question; less than 0.4 percent refused to respond to the question on life insurance.

\subsection{The Empirical Strategy}

For each treatment, we measure differences in take-up and coverage levels between the baseline scenario and the treatment scenario. Take-up is defined as the proportion electing any coverage, while the coverage level is measured using the average multiple of pay among the covered. The following regression model is used to estimate the effect of the treatment on takeup rates and coverage levels:

$$
T_{i b}=\propto+\beta_{1} \text { Treatment }_{i b}+\beta_{2} X_{i}+\varepsilon_{i b}
$$

where $T_{i b}$ is the take-up rate or coverage level of benefit $b$ by individual $i$. This is a function of the characteristics of the treatment individual $i$ received concerning benefit $b$ (Treatment $_{i b}$ ). It is also a function of individual characteristics $\left(X_{i}\right)$ that could influence demand for benefit $b$. These include age, income, education, gender, marital status, the existence of a young child in the household, home-ownership status, and pay-schedule. Since participants are randomly assigned to treatments in this study, $\mathrm{X}_{i}$ is expected to be evenly distributed among the treatment groups, thus unlikely to bias estimates of $\beta_{1}$. However, testing showed that a few groups might vary significantly from others with respect to individual characteristics which could influence demand for benefits, so all results presented control for $\mathrm{X}_{\mathrm{i}} \cdot \varepsilon_{i b}$ is a normally-distributed idiosyncratic error term. We estimate a probit model for the binary outcomes (take-up rate, select 65 percent of pay), and ordinary least squares model for continuous outcomes (coverage level). 
The effect of the treatment might vary based on personal characteristics. For example, families with young children might already believe they need life-insurance, and thus be more responsive to personalized insurance recommendations. To that end, we refine our model to include an interaction between individual characteristics, (expressed as binary variables) and the treatment.

$$
T_{i b}=\propto+\beta_{1} \text { Treatment }_{i b}+\beta_{2} \text { Treatment }_{i b} * X_{i}+\beta_{3} X_{i}+\varepsilon_{i b}
$$

The following characteristics are tested for heterogeneous treatment effects: earnings; gender; education; age; presence of young children in the household; marital status. ${ }^{5,6}$ Some of the treatments are expected to be strong for "naïve decision-makers," based on behavioral finance theory. Since we don't have a direct measure of this characteristic we rely on three proxies age, income, and education. We present marginal effects from a probit model for the binary outcomes, taking into account the non-linearities in the model (Ai and Norton 2003).

\subsection{Results of Behavioral Treatments}

4.3.1 Baseline Scenario. 75 percent of the baseline group elected to get life insurance coverage, about one percentage point higher than the life-insurance participation rate reported in Prudential (2011) survey of group benefits. The average coverage level is 4.5 times annual salary among those who elected coverage. The effects of the treatments are all compared to this baseline scenario, presented in Tables 4 and 5.

4.3.2 Defaults: Defaults fundamentally offer a path of least resistance - a path in which making a decision appears more difficult than the consequences of sticking with the status-quo (Choi, Laibson, and Metrick, 2001). People are more likely to choose this path of least resistance when a decision is hard to make and the consequences are not salient (e.g. they are in the distant future or unlikely to take place). Defaults can also function as advice, or a signal of importance (Madrian and Shea, 2001).

We expect defaults to raise coverage rates because 1) it is mentally taxing to figure out the right amount of life insurance; 2) The value of life insurance is hard to determine because

\footnotetext{
${ }^{5}$ The variables tested for heterogeneity in the treatment effect have all been associated with demand for life insurance in prior studies (see Zietz, 2003).

${ }^{6}$ Earnings are defined as a binary variable which equals 1 if above $\$ 75,000$, and 0 otherwise. Age is also defined as a binary variable which equals 1 if above 35 year-old, and 0 otherwise.
} 
people have a hard time estimating their risk of premature death; 3) The cost of sticking with the status quo is relatively minor because the life insurance premium charged for the default is equal to a few dollars a paycheck. We also expect defaults to lower coverage levels because people induced to get coverage because of the default are expected to stick to the default (1 times pay), which, in turn would lower the average coverage level among people with coverage.

The results are consistent with our hypothesis with respect to coverage rates: participation increases by 7 percentage points as a result of defaults. Interestingly, we see different impacts of the default based on income: those earning less than \$75,000 are 9 percentage points less likely to take coverage while those earning more than $\$ 75,000$ are 10 percentage points more likely to take-up insurance coverage when defaulted into it (Table 5). However, average coverage levels among those electing coverage did not drop as a result of the default, despite the fact that the percentage of people electing to cover one times their pay (the default option) doubled compared to the baseline scenario. This suggests the default prompted at least some people to get more coverage than they might have obtained without the default. These individuals may be interpreting the default as a recommended minimum coverage level and they have already determined that want more than the minimum, and thus increase their coverage accordingly.

\subsubsection{Checklist: Theory suggests a checklist will 1) increase coverage rates by increasing the} salience of the need for life insurance, and 2) increase coverage levels by increasing the salience of specific liabilities (the mortgage, student loans, auto loans, other debt, and future college costs in this case) and anchoring respondents to the average value of the liabilities presented in the checklist (Kahneman ,Tversky, and Slovic 1982). We also expect coverage rates to be higher among naïve decision-makers (for whom the need for life insurance is least salient). The checklist we presented showed national averages for mortgage balances, college expenses, etc. Thus we also expect people with lower-than-average income would experience a greater nudge to increase their coverage (the mortgage amount would appear relatively high) than those earning significantly more than the national average.

The results are partially consistent with these predictions. Providing a checklist raises overall coverage levels by 50 percent of salary, but its effect on coverage rates, while positive, is not statistically significant. Results of tests for heterogeneity in the response to the treatment 
contradict theory, as providing a checklist leads to a differentially higher take up rate among more educated people, and people who are married, at 7 and 6 percentage points respectively not groups that we ex ante classified as "naïve."

4.3.4. Personalized Estimate: A personalized estimate is expected to increase take-up rates and coverage levels primarily due to the anchoring effect, secondarily due to the signaling effect. Anchoring is expected to affect coverage levels and signaling is expected to affect both coverage rates and levels. Other studies have shown that naïve decision makers are more likely to be influenced by anchoring and signaling than experienced or expert decision-makers (Wilson, Houston, Etling, and Brekke, 1996).

We find that the personalized estimate increases participation by 6 percentage points, but does not increase coverage levels among the insured. This finding suggests that individuals induced to participate due to the personalized estimate do not act differently than those who already knew they needed life insurance coverage, and both groups pick similar coverage levels. Coverage levels do rise among people earning less than \$75,000 per year (a proxy for naïve decision-maker), and also rise among participants with young children in their households.

4.3.5. Link to calculator: A link to a calculator is expected to increase coverage rates and levels through the same mechanisms as an in-survey coverage recommendation. The recommendation provided by the tool is expected to act as an anchor, and also a signal of the importance of coverage. However, Belbase and Sass (2011) found that roughly half the participants presented with a link to a retirement estimator did not click on the link, and that a quarter of those who clicked on the link did not use the tool as intended. Thus the link to an online estimator is expected to have an overall smaller effect on coverage than the in-survey recommendation. Because the calculator uses more information than the in-survey recommendation, the calculator may be more effective among those who use it.

Overall coverage rates and levels do not change as a result of this treatment. However, coverage levels do increase, by almost $1 \mathrm{x}$ annual salary, among people with young children in the household. When these results are analyzed in conjunction with the results of the in-survey recommendation, it appears that information that is easily accessible when people elect coverage 
is more salient in the decision-making than information that is either hard to access or removed from the coverage election space.

\subsubsection{Two times pay employer provided insurance: Behavioral finance suggests two ways in} which a generous amount of free insurance might affect coverage: 1) as a signal of the importance of the benefit, which would lead to higher voluntary coverage rates, 2) as a signal of adequate coverage, which could lead to lower overall coverage levels. Independent of the behavioral affects, the employer-provided insurance might simply substitute for voluntary insurance, which would lead to lower voluntary participation rates.

Voluntary participation and coverage levels both decrease as a result of this treatment. Overall participation decreases by 11 percent, and the coverage levels drop by 50 percent of annual salary. Individuals who are unmarried are actually 22 percent less likely to participation in the market with the higher employer-sponsored coverage amount. However, employerprovided insurance did not completely offset voluntary coverage: the 11 percentage point decrease in voluntary coverage is only one-third of the proportion of people electing 2 times pay or less in the baseline case, and the decline in the voluntary coverage level is only 50 percent of annual salary, even though the employer provides two-times pay. In other words, total participation and coverage levels increase in response to an employer-provided base-level insurance benefit.

4.3.7 Annuity Information: Theory suggests information on annuities - in this case a table showing the lump-sum needed to buy various levels of monthly income for 15 years - will make monthly income needs more salient, increasing participation rates and coverage levels. The table showing lump-sum values is also likely to have an anchoring effect on coverage levels, generally raising levels because of the high cost of an annuity relative to average lump-sum coverage levels.

As expected, this treatment significantly increases coverage rates, by 8 percentage points. This treatment has the largest impact on participation of all the treatments tested. The increase in coverage rates is greatest among people earning over $\$ 75,000 /$ year - by almost 14 percentage points - a group shown to have a relatively higher preference for annuities by prior research. We 
do not, however, find evidence of an anchoring effect, as the average coverage level remains unchanged.

\subsubsection{Annuity information and Checklist: Combining a checklist and annuity information is} expected to increase participation beyond what is achieved by either treatment alone by making both monthly income needs and future liabilities salient during the decision-making process. The anchoring effect could increase or decrease coverage levels, depending on specific numbers participants pay attention to during the decision making process (Wilson, Houston, Etling, and Brekke, 1996).

The results suggest that this treatment has a significant impact on both take-up and coverage levels: 5 percent increase in take-up and an increase of almost 60 percent of salary in the coverage level. However, there is little additional value in combining these two treatments. While this treatment gained statistical significance over the checklist alone, the magnitude of the increase in participation and the increase in coverage levels are approximately the same. In other words, the additional annuity information does not appear to have a significant effect on coverage. However, in this treatment the checklist always appeared first, which may have contributed to its apparent weight in the decision process. Future work that randomizes the order of the checklist and the annuity information should be done to test the robustness of these results.

\subsection{Summary of the Results}

Compared to the baseline scenario, defaults, personalized estimates, and annuity information increase the overall coverage rates by 6 to 8 percentage points, while a higher employer match lowers the overall coverage rate by 11 percentage points. Coverage levels increase by 0.5 - 0.6 times pay when participants see a checklist of items that life insurance might cover, suggesting the important of salience of the information. Supplementary coverage falls by 0.5 times pay when the employer provides a larger base coverage level, but the total insurance coverage levels increase. Other treatments improve coverage levels only among specific subgroups. We find significant heterogeneity among respondents in the way and extent to which treatments affected coverage. Income, age, education, marital status, and the presence of a child in the household are identified as important factors influencing the response to one or more treatments. 


\section{Conclusions}

This paper set out to study how people make decisions about their life insurance purchases. Despite the decades of previous research, these in-depth interviews reveal a lot about how individuals make decisions about voluntary life insurance purchases. Importantly, these interviews highlight several barriers that prevent individuals from getting adequate coverage.

The need for insurance is clear in people's minds. They do not spend a lot of time on the decision, revisit it occasionally, often are prompted by the annual sign-up process or when good things happen in their life, such as marriage or child birth. However, individuals have a difficult time calculating how much life insurance coverage they should have. They largely rely on anchors - the employer default, the big-ticket items they are concerned about paying, or an agent recommendation - and adjust from there. Further, they are likely to ignore income replacement needs. This process could be due to the benefit being framed as a lump-sum, and thus individuals focus on the lump-sum uses of the death benefit, overlooking the annuity-type uses.

Since the right amount of coverage is difficult to calculate, some individuals rely on the price to determine how much life insurance to buy. They are largely unaware of "fair" prices, and instead they compare the price offered by their current employer to prices offered by previous employers or prices for other items in the group benefit package. In this way, life insurance appears very inexpensive. This perceived affordability leads individuals to decide on how much life insurance to buy based on a "painless amount” per paycheck, or framing it in terms of a foregone coffee or dinner out. This line of thinking is not helpful to get individuals to buy adequate insurance.

Armed with this information on how the decisions are made, we then investigate whether behavioral-finance concepts can assist people to make better decisions regarding their life insurance coverage. Using a randomized, controlled, online experiment we test the effectiveness of 7 treatments compared to a baseline benefit-enrollment scenario. The study identifies some promising treatments and sheds light on characteristics of interventions likely to be effective in improving life insurance coverage.

Four treatments successfully increased life-insurance participation: defaulting individuals into coverage, a personalized coverage estimate, an annuity to lump-sum translation chart, and providing a checklist of future liabilities and the annuity to lump-sum information. Only two treatments increased coverage levels among the insured: providing a personalized checklist, with 
and without the annuity to lump-sum conversion information. The only treatment that increased both the overall participation and the coverage levels was increasing the employer-sponsored insurance levels - not surprising given that this is the only option that did not include any increase in price. Treatments that changed individual's insurance elections had several factors in common: 1) The treatments were simple. As in easy to understand, concrete, and short; 2) The treatments were effortless. They did not require effort on the part of the participants; 3) The treatments made salient the right coverage level or the right factors to consider when electing coverage.

The treatments that did not impact life insurance coverage decisions are also informative. A link to an insurance calculator did not increase coverage, even though an in-survey insurance recommendation did increase coverage. This result suggests that where and when information is provided are important determinants of the effectiveness of information interventions. Second, adding annuity information after a checklist increased statistical significance by not the magnitude of coverage beyond simply using a checklist. This finding suggests people pay attention to a limited amount of information when electing benefits, therefore treatments need to be short.

We also find significant heterogeneity among respondents in the way and extent to which treatments affected coverage. Income, age, education, marital status, and the presence of a child in the household are identified as important factors influencing the response to one or more treatments and these factors should be carefully considered when testing these treatments in the field.

The results of this experiment suggest several avenues to pursue. We find several ways to overcome obstacles individuals face in choosing adequate insurance in a hypothetical decision framework; the challenge now lies in identifying treatments that will work best in the real-world. This process involves selecting the most practical treatments and implementing field trials in partnership with employers. 


\section{References}

American Council of Life Insurers (ACLI). 2013. “Life Insurers Fact Book 2012.” Available at: https://www.acli.com/Tools/Industry Facts/Life Insurers Fact Book/Documents/_factbook2012_entirety_020813.pdf.

Ai, Chunrong and Edward C. Norton. 2003. "Interaction Terms in Logit and Probit Models.” Economic Letters 80:123-129.

Barsky Robert, B., F. Thomas Juster, Miles S. Kimball, Matthew D. Shapiro. 1997. "Preference Parameters and Behavioral Heterogeneity: An Experimental Approach in the Health and Retirement Study.” The Quarterly Journal of Economics 112(2): 537-579.

Belbase, Anek and Sass, Steven, A. 2011. Testing "Target Your Retirement": Results from a Nationally Representative Internet Panel. Chestnut Hill, MA. Center for Retirement Research at Boston College.

Bernheim, B. Douglas. 1991. "How Strong are Bequest Motives? Evidence Based on Estimates of the Demand for Life Insurance and Annuities.” Journal of Political Economics 99: 899-927.

Bureau of Labor Statistics. 2013. Employee Benefits in the United States - March 2013. Available at: http://www.bls.gov/news.release/pdf/ebs2.pdf.

Burnett, J. J. and B. A. Palmer. 1984. "Examining Life Insurance Ownership Through Demographic and Psychographic Characteristics.” Journal of Risk and Insurance 51: 453-467.

Choi, James, J. Laibson, David, I., Madrian, Bridgitte, \& Metrick, Andrew. 2001. “Defined Contribution Pensions: Plan Rules, Participant Decisions, and the Path of Least Resistance.” Working Paper 8655. Cambridge, MA: National Bureau of Economic Research.

Couch, Christina. 2011. “Do You Need Supplemental Life Insurance?” (October 24). Bankrate.com. Available at: http://www.bankrate.com/finance/insurance/supplementallife-insurance-1.aspx.

Fitzgerald, John. 1987. "The Effects of Social Security on the Life Insurance Demand by Married Couples.” Journal of Risk and Insurance 54: 86-99.

Kahneman, Daniel and Tversky, Amos. 1979. "Prospect Theory: An Analysis of Decision under Risk.” Econometrica 47(2): 263-291.

Kahneman, Daniel and Tversky, Amos. 1986. "Rational Choice and the Framing of Decisions.” The Journal of Business 59(4:2): S251-S278. 
Kahneman, Daniel, Slovic, Paul, and Tversky, Amos. 1982. Judgement Under Uncertainty: Heuristics and Biases. New York, NY: Cambridge University Press.

Lewis, Frank D. 1989. “Dependents and the Demand for Life Insurance.” American Economic Review 79(3): 452-67.

LIMRA 2010. Trends in Life Insurance Ownership. Available at: http://www.limra.com/Posts/PR/News_Releases/Ownership_of_Individual_Life_Insuran ce_Falls to 50-Year_Low, LIMRA_Reports.aspx.

Madrian, Brigitte, C. and Shea, Dennis, F. 2001. “The Power of Suggestion: Inertia in 401(k) Participation and Savings Behavior.” The Quarterly Journal of Economics 116(4): 11491187.

Mullainathan, Sendhil and Thaler, H. Richard. 2000. “Behavioral Economics.” Working Paper 7948. Cambridge, MA: National Bureau of Economic Research.

Mussweiler, T., Englich, B., and Strack, F. 2004. “Anchoring Effect.” In R. Pohl, Cognitive illusions: A Handbook on Fallacies and Biases in Thinking, Judgment and Memory, 183200. New York, NY: Psychology Press.

Prudential Insurance. 2011. Sixth Annual Study of Employee Benefits: Today and Beyond. The Prudential Insurance Company of America. Newark, NJ. Available at: http://www.prudential.com/media/managed/StudyofEmployeeBenefits_TodayandBeyond 6th.pdf.

Tversky, A., and Kahneman, D. 1986. "Rational Choice and the Framing of Decisions.” The Journal of Business 59(4:2): S251-S278.

Wilson, Timothy, D. Houston, Christopher, E, Etling, Kathryn, M. and Brekke, Nancy. 1996. "Basic Anchoring and its Antecedents." Journal of Experimental Psychology: General 125(4): 387-402.

Yaari, Menahem E. 1965. "Uncertain Lifetime, Life Insurance, and the Theory of the Consumer.” Review of Economic Studies 32(2): 137-50.

Zietz, Emily Norman. 2003. “An Examination of the Demand for Life Insurance.” Risk Management and Insurance Review 6(2): 159-191. 


\section{Appendix A. Script for Life Insurance Interviews}

Hello. My name is and I am calling from Mathew Greenwald \& Associates in Washington, D.C. May I please speak to ? [READ NAME FROM RECRUITMENT.]

As you know, we are conducting a survey on behalf of Boston College's Center for Retirement Research. The purpose of the survey is to learn more about peoples' experiences with the employee benefits they can purchase at work.

As our recruiter told you, we will send you a $\$ 25$ honorarium if you complete this interview. The interview should take about 50 minutes to complete.

[ASK PERMISSION TO RECORD] Your responses will be confidential, and your name will not be connected with your specific responses. However, it is very helpful for us, for our notetaking purposes, if we can record our conversation. Only researchers will have access to the records, and they will be destroyed after 1 year. May I record our conversation?

Do you have any questions before we get started? You can stop me at any time and ask questions. Some of the questions address issues of disability and mortality, which you may find uncomfortable. You can refuse to answer questions or stop the survey at any time. This would have no impact on your current or future relationship with Boston College.

If you have no questions, we can begin. Do you give your consent to participate in this study?

\section{Background Questions}

1. To confirm, are you married? Counting your spouse and any children, how many people are financially dependent on your income?

2. Which of the following best describes the total amount of your household assets?

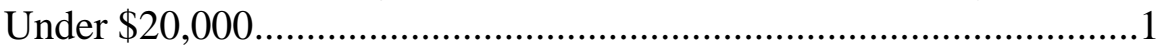

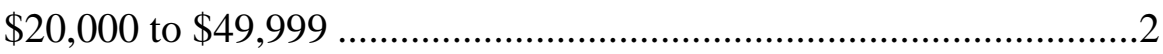

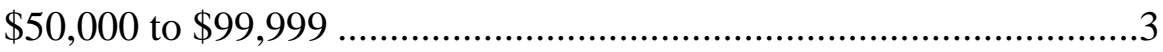

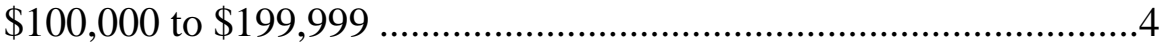

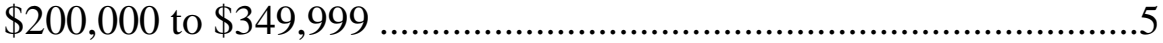

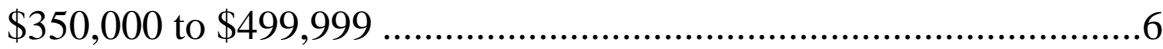

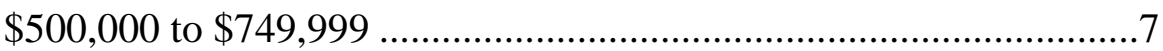

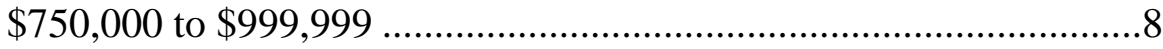

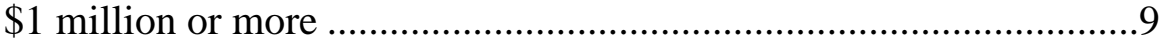

[VOL] Don't know/Refused.....................................................10 
3. I wanted to verify that your employer offers you the opportunity to buy life insurance and/or disability insurance? Is it standalone coverage or an additional benefit to what is already offered at no cost?

$\begin{array}{ll}\text { Life only: } & \\ \text { Disability only: } & \\ \text { Both: } & - \\ \text { Neither: } & \end{array}$

4. And to confirm what our recruiter asked you, which of these products have you purchased through work? When did you first purchase these?

Life only:

Disability only:

Both:

Neither:

5. Do you or your spouse have any other type of life or disability insurance?

- What are the sources of your life/disability insurance coverage?

- [IF HAVE LIFE or DISABILITY] How big a chunk of your total life/disability insurance coverage comes from the coverage you purchased at work?

6. How would you describe your financial situation/management? Do you live paycheck-topaycheck or have a rainy-day-fund to get you through tough times?

7. With your health and auto insurance policies, do you tend to get the most thorough coverage you can or do you tend to save money on premiums by having high deductibles? (Probe for specifics.)

Do you feel you have enough auto/homeowners coverage? Why/why not?

\section{Life Insurance}

Now I want to ask you some questions about your LIFE INSURANCE coverage.

8. How often do you think about whether your life insurance coverage is adequate? Do you feel that it is adequate? How did you figure this out?

9. How do/would you budget for life insurance?

Probe: Do you:

- Figure out how much you need and buy it from your employer?

- Pay for other expenses first and use what's left over? (if yes, which expenses?)

- Buy what you can get for a specific dollar amount you have in mind?

- Other approaches? 
10. [SKIP IF NO DEPENDENTS] How concerned are you that you might die while your family is still financially dependent on you?

- Do you feel like you're more or less likely to die compared to other people your age? why?

- How would your family manage financially if you were to die prematurely?

- Would this be catastrophic or manageable, financially speaking?

Probe: What concerns you most?

o Adequate income to pay the monthly bills?

o Paying off debt?

o Paying for college?

o Paying for your/your spouse's retirement?

o Maintaining current lifestyle?

o What existing insurances do you think would help?

11. Do you know what kind of coverage other's like you have, or what experts recommend for people in your situation? Do you care?

\section{Purchasing Life Insurance through Work}

12. I want to ask you about how your employer introduced the life insurance coverage and how you made your decision.

- Who introduced it -- an outside agent or an HR person? Did you trust their advice?

- How much time did you spend evaluating it? Did you seek any advice about it - if so, from whom/what sources?

- [IF PURCHASED] Was it easy or hard to sign-up? Did you have enough information and support?

- Do you think that the life insurance offered at work was reasonably priced? What makes you think this?

- Overall, what do you think of the way your employer handled the introduction of the life insurance benefit you could purchase? What would you do to make the process better?

13. [IF PURCHASED] Why did you choose to buy life insurance at work?

Probe:

o What are some features or terms of your policy that you find valuable? How important are features like convenience, payroll deduction, and the ability to continue your coverage after you leave your employer?

o What type of medical questions or testing is required to qualify for the coverage? Is it easy or hard to qualify?

14. [IF NOT PURCHASE] Why didn't you buy the insurance that was offered at work? Probe:

o Was it because you couldn't afford it or that you got better coverage elsewhere? 
o Were there specific concerns that you had with the coverage - cost, limits, insurability?

o [If did not get around to it/didn't think needed it] Did you perceive it would take a long time? Why don't you believe you need disability income insurance? Was there anything your employer/the provider could have done to help you overcome procrastination?

\section{Life Insurance Options [SKIP SECTION IF HAVE VOL. LI AND TIME IS SHORT]}

15. Now I want to talk a little more about the death benefit that life insurance pays out. Think of how your family will use this money.

- [IF PURCHASED] What will your benefits pay for?

- Would it be easier for your family to meet their financial needs if they received a one-time payment or if they received a regular monthly income for a fixed period (say 10 or 20 years)?

o Would it be easier for you to estimate how much life insurance to get if you could pick the payout to be a monthly amount for a period of years or a onetime payment?

- Would it be easier for your family to meet their financial needs if they could pay off concrete items with the death benefit? For example, big ticket item like a mortgage, a kid's college education, or other loans you might want to pay off.

o Would it be easier for you to estimate how much life insurance to get if you could pick the items you'd want them to be able to pay off?

o [IF DEPENDENTS/SPOUSE] What do you think of the idea of being able to purchase life insurance with your college and retirement savings plans to ensure that your children's college or your spouse's retirement savings continue after you die?

16. Life insurance policies can offer other features. Are any of the following features appealing to you?

- Benefits for staying insured with your provider - like credit card rewards or loyalty discounts.

- Financial counseling for survivors. 


\section{Appendix B. The Hypothetical Life Insurance Choice Survey}

\section{SP]}

[PROMPT ONCE IF REFUSED]

S1. Which of the following best describes your annual income before taxes?

1 .....Under 24,999

2.....25,000 or more

\section{[IF S1=1 OR REFUSE THEN TERMINATE, QFLAG=2]}

[NUMBER BOX, RANGE 0-50]

S2. How many children do you have?

[IF S2>0]

[NUMBER BOX, RANGE 0-99]

S3. How old is your youngest child?

\section{[SP]}

[PROMPT ONCE IF REFUSED]

S4. Which of the following best describes your annual salary before taxes?

$1 \ldots \$ 0-\$ 24,999$

$2 \ldots \$ 25,000-\$ 49,999$

3...\$50,000-\$74,999

4 ...\$75,000-\$99,999

$5 . . \$ 100,000-\$ 124,999$

$6 . . . \$ 125,000-\$ 149,999$

$7 \ldots \$ 150,000-\$ 174,999$

$8 . . . \$ 175,000-\$ 199,999$

$9 . . \$ 200,000$ or higher

\section{[IF S4= REFUSED THEN TERMINATE, QFLAG=2]}

\section{[SP]}

\section{[PROMPT ONCE IF REFUSED]}

S5. Which of the following best describes your spouse's annual salary before taxes?

$1 \ldots \$ 0-\$ 24,999$

2...\$25,000-\$49,999

$3 \ldots \$ 50,000-\$ 74,999$

$4 \ldots \$ 75,000-\$ 99,999$

$5 . . \$ 100,000-\$ 124,999$

6 ...\$125,000-\$149,999

$7 \ldots \$ 150,000-\$ 174,999$

$8 . . . \$ 175,000-\$ 199,999$

$9 . . \$ 200,000$ or higher 
S6. How often do you receive a paycheck or direct deposit of your paycheck from your employer?

1 ...Weekly

2...Twice a month

3...Monthly

[Sample to be split into 11 groups of 400, each group gets one Life Insurance question.] [For all questions, answer options were reversed for half of the respondents]

\section{Life Insurance Tests}

\section{Baseline case}

“Imagine you are enrolling in benefits for a new employer. You're offered the chance to buy life and disability insurance as part of your benefit package. Please read through each option and select the one you'd be most likely to pick."

Q1. You've worked hard to build a good life. There's a lot to protect. Now is the perfect time to evaluate your life insurance needs so your loved ones can live forward with their hopes and dreams.

Your employer offers the following life-insurance options. Which one will you pick?

ㅁ No coverage.

1 times your annual salary, or $\$ X X X$ at a cost of $\$ Y$.YY per paycheck.

2 times your annual salary, or $\$ X X X$ at a cost of $\$ Y$.YY per paycheck.

3 times your annual salary, or \$XXX at a cost of \$Y.YY per paycheck.... [UP TO 12 TIMES ANNUAL SALARY]

Test \# 1: Defaults

"Imagine you are enrolling in benefits for a new employer. You're offered the chance to buy life and disability insurance as part of your benefit package. Please read through each option and select the one you'd be most likely to pick.”

Q2. You've worked hard to build a good life. There's a lot to protect. Now is the perfect time to evaluate your life insurance needs so your loved ones can live forward with their hopes and dreams.

Your employer offers the following life-insurance options. Which one will you pick?

$\checkmark 1$ times your annual salary, or \$XXX at a cost of \$Y.YY per paycheck [default]

$\square$ No coverage.

प 2 times your annual salary, or \$XXX at a cost of \$Y.YY per paycheck.

3 times your annual salary, or $\$ X X X$ at a cost of $\$ Y$.YY per paycheck.

4 times your annual salary, or \$XXX at a cost of \$Y.YY per paycheck.... [UP TO 12 TIMES YOUR ANNUAL SALARY]

\section{Test \# 2 Checklist}

"Imagine you are enrolling in benefits for a new employer. You're offered the chance to buy life and disability insurance as part of your benefit package. Please read through each option and select the one you'd be most likely to pick." 
Q3. You've worked hard to build a good life. There's a lot to protect. Now is the perfect time to evaluate your life insurance needs so your loved ones can live forward with their hopes and dreams.

Use the checklist below to get a sense of how much life insurance you'd need to protect your loved ones. Keep in mind that the figures below are averages, and you might need more or less coverage based on the number of kids you have, whether your spouse works, your personal level of debt, and your plans for the future.

\begin{tabular}{|l|l|}
\hline Item & Average Cost \\
\hline Mortgage & $\$ 250,000$ \\
\hline Auto-Loan & $\$ 24,000$ \\
\hline Student Loan & $\$ 25,000$ \\
\hline Credit Cards & $\$ 2,500$ \\
\hline 4 year in-state tuition & $\$ 60,000$ per child \\
\hline
\end{tabular}

Your employer offers the following life-insurance options. Which one will you pick?

$\square$ No coverage.

口 1 times your annual salary, or $\$ X X X$ at a cost of $\$ Y$.YY per paycheck.

2 times your annual salary, or $\$ X X X$ at a cost of $\$ Y$.YY per paycheck.

口 3 times your annual salary, or \$XXX at a cost of \$Y.YY per paycheck....[UP TO 12 TIMES YOUR ANNUAL SALARY]

\section{Test \# 3: Personalized estimate}

"Imagine you are enrolling in benefits for a new employer. You're offered the chance to buy life and disability insurance as part of your benefit package. Please read through each option and select the one you'd be most likely to pick."

Q4. You've worked hard to build a good life. There's a lot to protect. Now is the perfect time to evaluate your life insurance needs so your loved ones can live forward with their hopes and dreams.

Experts recommend $\$ X X X, X X X$ of life insurance for a typical [age] year old [male/female] with [\# of children] making your salary. [where $\$ X X X, X X X$ is a function of age, marital status, and each spouse's salary].

You'll need less than this amount if you tend to save more than 10 percent of your income, have paid off your mortgage, or have already saved for future expenses like college and retirement.

You'll need more if you tend to live paycheck-to-paycheck, have significant personal debt, or have not saved for future expenses like college and retirement.

Your employer offers the following life-insurance options. Which one will you pick?

$\square$ No coverage.

$\square 1$ times your annual salary, or $\$ X X X$ at a cost of $\$ Y$.YY per paycheck.

$\square 2$ times your annual salary, or $\$ X X X$ at a cost of $\$ Y$.YY per paycheck. 
口 3 times your annual salary, or \$XXX at a cost of \$Y.YY per paycheck.... [UP TO 12 TIMES YOUR ANNUAL SALARY]

\section{Test \# 4: Link to calculator}

"Imagine you are enrolling in benefits for a new employer. You're offered the chance to buy life and disability insurance as part of your benefit package. Please read through each option and select the one you'd be most likely to pick.”

Q5. You've worked hard to build a good life. There's a lot to protect. Now is the perfect time to evaluate your life insurance needs so your loved ones can live forward with their hopes and dreams.

You can find out how much life insurance is needed to protect your family's lifestyle in a few simple steps. Just follow this link: https://isso.prudential.com/simplifiedneeds/life to our personalized insurance estimator. You will be asked for some basic information about yourself in the tool before you get a life insurance estimate. Please return to the survey after reviewing your personalized estimate.”

Your employer offers the following life-insurance options. Which one will you pick?

$\square$ No coverage.

1 times your annual salary, or $\$ X X X$ at a cost of $\$ Y$.YY per paycheck.

2 times your annual salary, or \$XXX at a cost of \$Y.YY per paycheck.

3 times your annual salary, or \$XXX at a cost of \$Y.YY per paycheck.... [UP TO 12

\section{TIMES YOUR ANNUAL SALARY]}

Test \# 5: Employer provides 2x pay

"Imagine you are enrolling in benefits for a new employer. You're offered the chance to buy life and disability insurance as part of your benefit package. Please read through each option and select the one you'd be most likely to pick.”

Q6. You've worked hard to build a good life. There's a lot to protect. Now is the perfect time to evaluate your life insurance needs so your loved ones can live forward with their hopes and dreams.

Your employer provides you with Life Insurance worth 2 times your annual salary. In addition, you are offered the option to buy additional coverage (listed below). Which option will you pick?

ㅁ No additional coverage.

1 times your annual salary, or $\$ X X X$ at a cost of $\$ Y$.YY per paycheck.

2 times your annual salary, or $\$ X X X$ at a cost of $\$ Y$.YY per paycheck.

口 3 times your annual salary, or \$XXX at a cost of \$Y.YY per paycheck.... [UP TO 12 TIMES YOUR ANNUAL SALARY] 


\section{Test \# 6: Annuity information}

"Imagine you are enrolling in benefits for a new employer. You're offered the chance to buy life and disability insurance as part of your benefit package. Please read through each option and select the one you'd be most likely to pick.”

Q9. Life Insurance will replace your income when you're not around. But it might be hard to know how much life insurance will buy your family the monthly income they'll need to replace your paycheck.

Use the chart below to get an idea of how much insurance you'd need to buy to get fixed monthly income over a 15 year period.

\begin{tabular}{|l|l|}
\hline Monthly income over 15 years & Insurance required to get this income \\
\hline$\$ 1,000$ & $\$ 160,000$ \\
\hline$\$ 2,000$ & $\$ 320,000$ \\
\hline$\$ 3,000$ & $\$ 480,000$ \\
\hline$\$ 4,000$ & $\$ 640,000$ \\
\hline$\$ 5,000$ & $\$ 800,000$ \\
\hline$\$ 6,000$ & $\$ 960,000$ \\
\hline
\end{tabular}

Your employer offers the following life-insurance options. Which one will you pick?

$\square$ No coverage.

$\square 1$ times your annual salary, or $\$ X X X$ at a cost of $\$ Y$.YY per paycheck.

$\square 2$ times your annual salary, or $\$ X X X$ at a cost of $\$ Y$.YY per paycheck.

$\square 3$ times your annual salary, or $\$ X X X$ at a cost of $\$ Y . Y Y$ per paycheck... [up to 12 times your annual salary].

\section{Test \# 7 Checklist and Annuity}

"Imagine you are enrolling in benefits for a new employer. You're offered the chance to buy life and disability insurance as part of your benefit package. Please read through each option and select the one you'd be most likely to pick.”

Q11. You've worked hard to build a good life. There's a lot to protect. Now is the perfect time to evaluate your life insurance needs so your loved ones can live forward with their hopes and dreams.

Life insurance can be used to pay off debt and big-ticket expenses, like college. It can also be used to pay for day-to-day living expenses. To figure out how much you need:

First: use the checklist below to get a sense of how much life insurance you'd need pay off debt and college costs. Keep in mind that the figures below are averages, and you might need more or less coverage based on the number of kids you have, whether your spouse works, your personal level of debt, and your plans for the future.

\begin{tabular}{|l|l|}
\hline Item & Average Cost \\
\hline Mortgage & $\$ 170,000$ \\
\hline Auto-Loan & $\$ 15,000$ \\
\hline
\end{tabular}




\begin{tabular}{|l|l|}
\hline Student Loan & $\$ 29,000$ \\
\hline Credit Cards & $\$ 5,500$ \\
\hline 4 year in-state tuition & $\$ 25,000$ per child \\
\hline
\end{tabular}

Next: Use the chart below to get an idea of how much insurance you'd need to buy to get fixed monthly income over a 15 year period.

\begin{tabular}{|l|l|}
\hline Monthly income over 15 years & Insurance required to get this income \\
\hline$\$ 1,000$ & $\$ 160,000$ \\
\hline$\$ 2,000$ & $\$ 320,000$ \\
\hline$\$ 3,000$ & $\$ 480,000$ \\
\hline$\$ 4,000$ & $\$ 640,000$ \\
\hline$\$ 5,000$ & $\$ 800,000$ \\
\hline$\$ 6,000$ & $\$ 960,000$ \\
\hline
\end{tabular}

Your employer offers the following life-insurance options. Which one will you pick?

$\square$ No coverage.

口 1 times your annual salary, or $\$ \mathrm{XXX}$ at a cost of $\$ Y$.YY per paycheck.

2 times your annual salary, or $\$ X X X$ at a cost of $\$ Y$.YY per paycheck.

口 3 times your annual salary, or $\$ X X X$ at a cost of $\$ Y$.YY per paycheck.... [up to $\mathbf{N}$ times your annual salary]. 
Table 1. Descriptive Statistics of the In-Depth Interview Sample

\begin{tabular}{|c|c|c|}
\hline & $\begin{array}{c}\text { Total } \\
\mathrm{N}=24 \\
\end{array}$ & $\begin{array}{c}\text { Parents } \\
\mathrm{N}=16\end{array}$ \\
\hline \multicolumn{3}{|l|}{ Information from screener } \\
\hline Age & & N/A \\
\hline $21-30$ & $8 \%$ & \\
\hline $31-40$ & $29 \%$ & \\
\hline $41-50$ & $29 \%$ & \\
\hline $50+$ & $33 \%$ & \\
\hline Household income & & N/A \\
\hline$\$ 10,000-\$ 49,999$ & $12.5 \%$ & \\
\hline$\$ 50,000-\$ 74,999$ & $25.0 \%$ & \\
\hline$\$ 75,000-\$ 99,999$ & $25.0 \%$ & \\
\hline$\$ 100,000-\$ 149,999$ & $37.5 \%$ & \\
\hline$\$ 150,000-\$ 199,999$ & $0.0 \%$ & \\
\hline$\$ 200,000-\$ 249,999$ & $0.0 \%$ & \\
\hline \multicolumn{3}{|l|}{ Demographic characteristics } \\
\hline Married & $88 \%$ & $94 \%$ \\
\hline Average number of dependents & 3.4 & 3.9 \\
\hline Male & $52 \%$ & $56 \%$ \\
\hline Have children & $78 \%$ & $100 \%$ \\
\hline Average number of children & 1.9 & 2.1 \\
\hline \multicolumn{3}{|l|}{ Financial characteristics } \\
\hline \multicolumn{3}{|l|}{ Net worth } \\
\hline under $\$ 20,000$ & $4 \%$ & $6 \%$ \\
\hline$\$ 20,000-\$ 49,999$ & $9 \%$ & $6 \%$ \\
\hline$\$ 50,000-\$ 99,999$ & $30 \%$ & $29 \%$ \\
\hline$\$ 100,000-\$ 199,999$ & $22 \%$ & $29 \%$ \\
\hline$\$ 200,000-\$ 349,999$ & $13 \%$ & $12 \%$ \\
\hline$\$ 350,000-\$ 99,999$ & $9 \%$ & $12 \%$ \\
\hline$\$ 500,000-\$ 749,999$ & $9 \%$ & $6 \%$ \\
\hline$\$ 750,000-\$ 999,999$ & $0 \%$ & $0 \%$ \\
\hline$\$ 1$ million or more & $4 \%$ & $0 \%$ \\
\hline Paycheck-to-paycheck & $36 \%$ & $39 \%$ \\
\hline \multicolumn{3}{|l|}{ Risk aversion } \\
\hline high deductible auto & $47 \%$ & $39 \%$ \\
\hline high deductible health & $26 \%$ & $17 \%$ \\
\hline \multicolumn{3}{|l|}{ Life insurance } \\
\hline Offered life & $100 \%$ & $100 \%$ \\
\hline Purchased life through work & $46 \%$ & $39 \%$ \\
\hline Purchased life insurance on own & $58 \%$ & $50 \%$ \\
\hline
\end{tabular}

Note: N/A = Not available for the subsample of parents. 
Table 2. Life Insurance Scenarios

Participants are presented with 13 options, ranging from no coverage

Baseline (control) to 12 times pay. The order of the options is randomized (high to low or low to high). No option is pre-selected.

1) Defaults Coverage of one times pay is pre-selected for participants. Participants are presented with a list of liabilities and the average

2) Checklist amount per liability that life insurance is commonly used to pay for, such as the mortgage, student loans, car payments, and future college expenses.

3) Personalized Participants are presented with a recommended level of coverage estimate based on their income, their spouse's income, and their age. Participants are presented with a link to a major insurance carrier's

4) Link to calculator calculator, which provides a personalized estimate of life insurance need based on numerous factors. Participants would then need to go back to the survey.

5) Employer provides Participants are informed that their employer provides two times their two-times pay annual pay in coverage at no cost to the employee.

6) Annuity information Participants are presented with a chart indicating how much insurance is needed to buy a 15-year, monthly fixed annuity of various sizes.

7) Checklist and Participants are shown both the Checklist of liabilities, followed by annuity information the Annuity information described earlier. 
Table 3. Selected Internet Panel Sample Demographics, Compared to Non-Respondents and the Current Population Survey (CPS)

\begin{tabular}{|c|c|c|c|c|c|c|}
\hline & \multicolumn{2}{|c|}{$\begin{array}{l}\text { Respondents } \\
(\mathrm{N}=4,581)\end{array}$} & \multicolumn{2}{|c|}{$\begin{array}{l}\text { Non-respondents } \\
(\mathrm{N}=3,885)\end{array}$} & \multicolumn{2}{|r|}{ CPS } \\
\hline & & $95 \%$ & & $95 \%$ & & $95 \%$ \\
\hline & Mean & $\begin{array}{l}\text { Confidence } \\
\text { Interval }\end{array}$ & Mean & $\begin{array}{l}\text { Confidence } \\
\text { Interval }\end{array}$ & Mean & $\begin{array}{l}\text { Confidence } \\
\text { Interval }\end{array}$ \\
\hline Age & 48 & $47-48$ & 44 & $43-44$ & 44 & $44-44$ \\
\hline Female (\%) & 42 & $41-43$ & 51 & $49-53$ & 44 & $43-44$ \\
\hline Married (\%) & 76 & $75-78$ & 74 & $72-75$ & 79 & $69-70$ \\
\hline Household size & 2.8 & $2.7-2.8$ & 3.0 & $2.9-3.0$ & 2.9 & 2.9-2.9 \\
\hline More than high school (\%) & 61 & $60-63$ & 50 & $49-52$ & & \\
\hline Homeowner (\%) & 84 & 83-85 & 78 & 77-79 & 79 & $79-80$ \\
\hline Median HH income (\$) & 97,676 & $96,331-99,042$ & 86,809 & $85,286-88,332$ & & \\
\hline Salary (\$) & 78,000 & $77,150-79,602$ & & & 64,376 & 63,874-64,905 \\
\hline
\end{tabular}

Note: Samples are restricted to employed respondents between the ages of 18 and 75 earning at least $\$ 25,000$ per year.

Sources: Authors’ calculations; and U.S. Census Bureau, Current Population Study (2011). 
Table 4. Change in Overall Take-Up Rates and Coverage Levels

\begin{tabular}{|c|c|c|c|c|c|c|}
\hline & \multirow[b]{2}{*}{ Mean } & \multicolumn{2}{|c|}{ Take-up } & \multicolumn{3}{|c|}{ Coverage level among insured } \\
\hline & & $\begin{array}{c}\text { Marginal } \\
\text { effect }\end{array}$ & Standard error & Mean & $\begin{array}{l}\text { Coefficient } \\
\text { (times pay) }\end{array}$ & Standard error \\
\hline Baseline & $75 \%$ & & & 4.48 & & \\
\hline Defaults & & 0.069 & $(0.027)^{* *}$ & & -0.258 & $(0.248)$ \\
\hline Checklist & & 0.044 & $(0.027)$ & & 0.501 & $(0.258)^{*}$ \\
\hline Personalized estimate & & 0.064 & $(0.027)^{* *}$ & & 0.157 & $(0.250)$ \\
\hline Link to calculator & & 0.015 & $(0.029)$ & & 0.05 & $(0.266)$ \\
\hline Employer provides two-times salary & & -0.11 & $(0.030)^{* * *}$ & & -0.498 & $(0.260)^{*}$ \\
\hline Annuity information & & 0.083 & $(0.027)^{* * *}$ & & -0.037 & $(0.248)$ \\
\hline Annuity and checklist information & & 0.053 & $(0.028)^{*}$ & & 0.573 & $(0.258)^{* *}$ \\
\hline
\end{tabular}

Notes: Stars indicate significance at the 10 percent $(*), 5$ percent $(* *)$, and 1 percent $(* * *)$ level. Take-up regressions are estimated with a probit model; Coverage level regressions are estimated using ordinary least squares among individuals electing coverage. All regressions also include controls for age, income, education, gender, marital status, presence of young child in household, home-ownership status, and pay-schedule.

Source: Authors' calculations. 
Table 5. Heterogeneity of the Treatment Effect

\begin{tabular}{|c|c|c|c|c|c|c|c|c|c|c|c|}
\hline & Baseline & $\begin{array}{l}\text { Under } \\
\$ 75,000\end{array}$ & $\begin{array}{c}\text { Over } \\
\$ 75,000\end{array}$ & $\begin{array}{c}\text { Under } \\
35\end{array}$ & $\begin{array}{c}\text { Over } \\
35\end{array}$ & $\begin{array}{l}\text { Up to } \\
\text { HS }\end{array}$ & $\begin{array}{c}\text { More } \\
\text { than HS }\end{array}$ & Unmarried & Married & $\begin{array}{c}\text { No child } \\
2-12\end{array}$ & $\begin{array}{l}\text { Child } \\
2-12 \\
\end{array}$ \\
\hline \multicolumn{12}{|l|}{ Panel A: Take-up } \\
\hline Defaults & $0.069 * *$ & -0.09 & 0.102 & & & & & & & & \\
\hline Personalized estimate & $0.064 * *$ & & & & & & & & & & \\
\hline Link to calculator & -- & & & & & & & & & & \\
\hline Annuity information & $0.083 * * *$ & -0.014 & 0.137 & & & & & & & & \\
\hline information & $0.053 *$ & & & & & & 0.08 & & 0.073 & & \\
\hline \multicolumn{12}{|l|}{ Panel B: Coverage } \\
\hline Defaults & -- & & & & & & & & & & \\
\hline Annuity information & -- & & & & & & & & & & \\
\hline $\begin{array}{l}\text { Annuity and checklist } \\
\text { information }\end{array}$ & $0.573 * *$ & & & & & & & & & & \\
\hline
\end{tabular}

Notes: Estimated effects significant at the $10 \%$ level or above are shown. Take-up regressions are estimated with a probit model; Coverage level regressions are estimated using ordinary least squares among individuals electing coverage. All regressions also include controls for age, income, education, gender, marital status, presence of young child in household, home-ownership status, and pay-schedule.

Source: Authors’ calculations. 
Figure 1. Life Insurance: How Do You Budget?

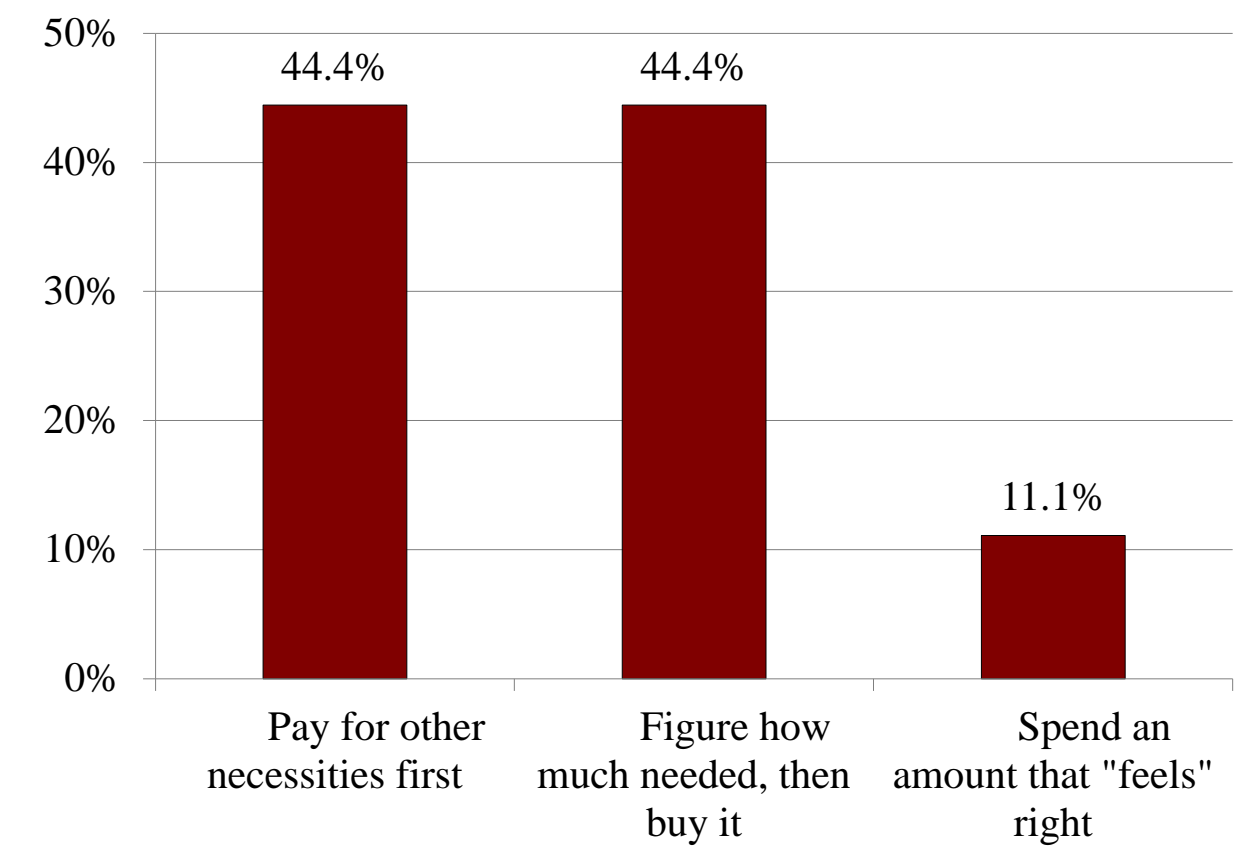

Source: Authors’ calculations from 24 in-depth interviews.

Figure 2. What Big Ticket Items Do You Use to Calculate How Much Life Insurance You Need?

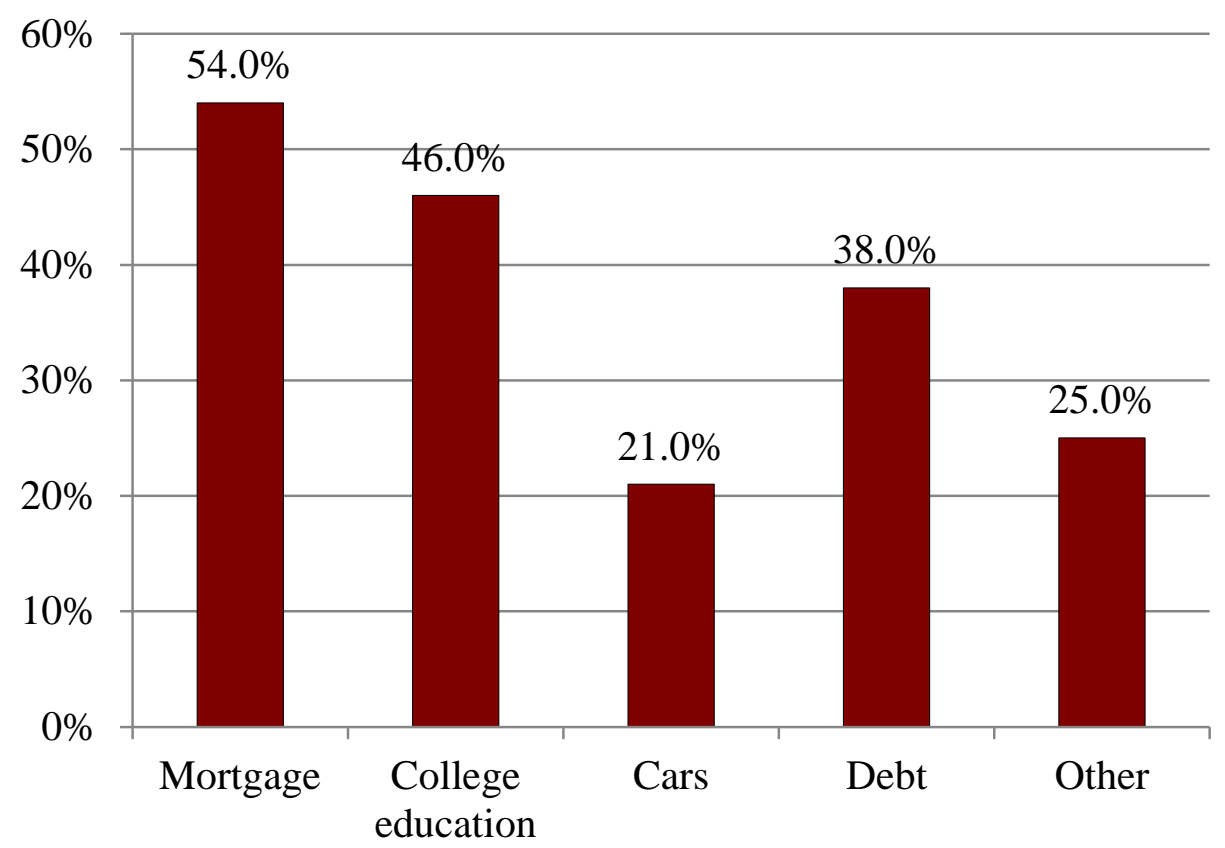

Source: Authors' calculations from 24 in-depth interviews. 


\section{RECENT WORKING PAPERS FROM THE CENTER FOR RETIREMENT RESEARCH AT BOSTON COLLEGE}

How Do People Decide on Life Insurance and Long-Term Disability Insurance Coverage? Norma B. Coe and Anek Belbase, June 2015

What Do Subjective Assessments of Financial Well-Being Reflect?

Steven A. Sass, Anek Belbase, Thomas Cooperrider, and Jorge D. Ramos-Mercado, March 2015

The Impact of Leakages from 401(k)s and IRAs

Alicia H. Munnell and Anthony Webb, February 2015

Recruiting and Retaining High-Quality State and Local Workers: Do Pensions Matter? Alicia H. Munnell, Jean-Pierre Aubry, and Geoffrey T. Sanzenbacher, January 2015

Do Tax Incentives Increase 401(k) Retirement Saving? Evidence from the Adoption of Catch-Up Contributions

Matthew S. Rutledge, April Yanyuan Wu, and Francis M. Vitagliano, November 2014

Are Retirees Falling Short? Reconciling the Conflicting Evidence

Alicia H. Munnell, Matthew S. Rutledge, and Anthony Webb, November 2014

Lifetime Job Demands, Work Capacity at Older Ages, and Social Security Benefit Claiming Decisions

Lauren Hersch Nicholas, November 2014

Who Is Internationally Diversified? Evidence from 296 401(k) Plans

Geert Bekaert, Kenton Hoyem, Wei-Yin Hu, and Enrichetta Ravina, November 2014

The Causes and Consequences of Financial Fraud Among Older Americans

Keith Jacks Gamble, Patricia Boyle, Lei Yu, and David Bennett, November 2014

New Evidence on the Risk of Requiring Long-Term Care

Leora Friedberg, Wenliang Hou, Wei Sun, Anthony Webb, and Zhenyu Li, November 2014

SSI at 62: Protecting the Vulnerable When Increasing Social Security's Early Entitlement Age

Norma B. Coe and April Yanyuan Wu, June 2014

Why Do SSI and SNAP Enrollments Rise in Good Economic Times and Bad?

Matthew S. Rutledge and April Yanyuan Wu, June 2014

All working papers are available on the Center for Retirement Research website

(http://crr.bc.edu) and can be requested by e-mail (crr@bc.edu) or phone (617-552-1762). 